\title{
Biosynthesis of silver nanoparticles from Schizophyllum radiatum HE 863742.1: their characterization and antimicrobial activity
}

\author{
Ram Prasad Metuku - Shivakrishna Pabba • \\ Samatha Burra • S. V. S. S. S. L. Hima Bindu N • \\ Krishna Gudikandula • M. A. Singara Charya
}

Received: 27 November 2012 / Accepted: 7 May 2013/Published online: 9 June 2013

(C) The Author(s) 2013. This article is published with open access at Springerlink.com

\begin{abstract}
Development of reliable and eco-friendly process for synthesis of silver nanoparticles is an important step in the field of application in nanotechnology. One of the options to achieve this objective is to use natural biological processes. They have an advantage over conventional methods involving chemical agents associated with environmental toxicity. This study demonstrates the extracellular synthesis of stable silver nanoparticles using the white rot fungus, Schizophyllum radiatum with GenBank Accession no HE 863742.1. The supernatant of the seed media obtained after separating the cells has been used for the synthesis of silver nanoparticles. The morphology and structure of synthesized silver nanoparticles were characterized using FT-IR, XRD, UV-visible spectrum of the aqueous medium containing silver ion showed a peak in the range of $420-430 \mathrm{~nm}$ corresponding to the Plasmon absorbance of silver nanoparticles. Scanning electron microscopy micrograph showed formation of well-dispersed silver nanoparticles in the range of 10-40 nm. The effect of different carbon sources and the time taken for formation particles and the anti-microbial activity of synthesized nanoparticles were carried and compared with silver nitrate solution and with standard streptomycin. The process of reduction being extra-cellular and fast may lead to the development of an easy bioprocess for synthesis of silver nanoparticles.
\end{abstract}

R. P. Metuku - S. Pabba · S. Burra ·

S. V. S. S. S. L. Hima Bindu N · K. Gudikandula .

M. A. Singara Charya $(\square)$

Department of Microbiology, Kakatiya University,

Hanamkonda, Warangal 506009, India

e-mail: mascharya@gmail.com
Keywords White rot fungi - Silver nanoparticles · Antimicrobial activity $\cdot$ Scanning electron microscopy

\section{Introduction}

Nanobiotechnology attempts to utilize biological templates in the development of nano-scaled products for diverse and specialized applications. Nanoparticles are clusters of atoms in the size range of 1-100 $\mathrm{nm}$. Increasing concern in green chemistry approaches for nanomaterial synthesis and process technology development has provided additional impetus for bioprocess studies using both prokaryotic bacterial cells and eukaryotic organisms (Bhattacharya and Gupta 2005). The size, shape and intercalation properties are the attributes of nanomaterials. The whole cell and cellular biomolecules have evolved as one of the best ways for generation and functionalization in the nanocomposite (Agag and Takeichi 2000). Biological organisms can be used as the environmental friendly techniques to create predictable nanoparticles. Silver and gold nanoparticles synthesized extra-cellularly that have the potentials in the opto electronic devices, thin films and non linear optics (Dahl et al. 2007). Macromolecules like enzymes and polysaccharides from the bioprocesses are increasingly in focus for nanomaterial production and utilization. Bacteriorhodopsin is one of the extensively studied nanomaterials for technical application, including in photoelectric and proton transport devices (Hampp 2004). Silver nanoparticles are in demand for the photo chemical applications, catalysis, and chemical analysis. The microbial silver bio-inorganics were studied intensively (Lengke et al. 2007; Shiying et al. 2007; Morones et al. 2005). The applications of AgNPs are of great concern in waste water treatment, pesticide degradation, killing human pathogenic 
bacteria (Kuber and Souza 2006). They exhibited cytoprotectivity toward HIV-1 infected cells (Elechiguerra et al. 2005). The study of biosynthesis of nanomaterials offers a valuable contribution as eco-friendly technologies into material chemistry. The ability of some microorganisms such as bacteria and fungi to control the synthesis of metallic nanoparticles should be employed in the search for new materials (Mandal et al. 2006).

This study was on the potentials of extra-cellular biosynthesis of silver nanoparticles by Schizophyllum radiatum and their characterization, antimicrobial activity on Gram-positive and Gram-negative bacteria. The influence of carbon sources on the silver nanoparticles biosynthesis was carried out. The S. radiatum was also studied for its antimicrobial and antioxidative properties under submerged fermentation. The supernatant of the seed media obtained after separating the mycelia has been used for the synthesis of silver nanoparticles.

\section{Materials and methods}

\section{Chemicals}

Dextrose, silver nitrate Merck (Germany) Malt extract was procured from Himedia (India). Sterile distilled water was used throughout the experiments.

\section{Collection and molecular identification}

of Schizophyllum radiatum

Fungi in the form of fruit body were collected from the Eturnagaram forest of Warangal, Andhra Pradesh, India. The fruit body was cleaned with disinfectants and approximately $3 \times 3 \mathrm{~mm}$ was placed on MEA agar medium in petri-dishes. When the mycelium had grown on the medium in the vicinity of the tissues, the sample was transferred to fresh agar media in tubes. This was repeatedly carried out until pure culture was obtained. Molecularbased characterization on ribotyping of $18 \mathrm{~S}$ rRNA was performed at the Xcelris Genomics, Ahmedabad, India and sequence was deposited to EMBL database for accession number.

Production of extra-cellular silver nanoparticles

Schizophyllum radiatum was grown in yeast malt broth containing dextrose $10 \mathrm{~g} \mathrm{l}^{-1}$, malt extract $5 \mathrm{~g} \mathrm{l}^{-1}$. The final $\mathrm{pH}$ was adjusted to 6.0. The flasks were incubated in the orbital shaker at $200 \mathrm{rpm}$ at $32{ }^{\circ} \mathrm{C}$. After 5 days of incubation, the mycelium was separated by filtration and supernatant was challenged with equal amount of with various concentrations $(0.5,1.0,1.5,2.0,2.5 \mathrm{mM})$ of silver nitrate solution (prepared in deionized water) and incubated in shaker at $200 \mathrm{rpm}$ in dark condition at $32{ }^{\circ} \mathrm{C}$. Simultaneously, a positive control of silver nitrate solution and deionized water and a negative control containing only silver nitrate solution were maintained under same conditions.

Influence of carbon sources on silver nanoparticle synthesis

In order to investigate the influence of carbon sources on the silver nanoparticle synthesis, the time taken for the formation of particles (i.e. from colorless to brown) was studied. Sources like glucose, fructose, sucrose, lactose, and starch were added separately in place of dextrose at a concentration of $0.4 \%$ to the basal medium containing malt extract $(1 \%)$. $S$. radiatum was inoculated into the basal medium containing particular carbon source and incubated at $32{ }^{\circ} \mathrm{C}$ for 5 days at $200 \mathrm{rpm}$ in orbital shaker. After incubation, the culture broth was filtered and separated the mycelial biomass. Supernatant was challenged with equal volume of effective concentration of $\mathrm{AgNO}_{3}$ solution. Control consisting of filtered broth of particular carbon source and deionized water was maintained under same conditions.

UV-visible spectral analysis

Change in color was observed in the silver nitrate solution incubated with the $S$. radiatum. The UV-visible spectra of this solution were recorded in ELICO SL-159 Spectrophotometer in the range of $350-470 \mathrm{~nm}$.

Scanning electron microscope

After freeze drying of the purified silver particles, the size and shape were analyzed by scanning electron microscopy (JOEL-Model 6390).

Fourier-transform infrared (FT-IR) chemical analysis

Fourier-Transform Infra-Red spectroscopy measurements, the biotransformed products present in extracellular filtrate were freeze-dried and diluted with potassium bromide in the ratio of 1:100. The FT-IR spectrum of samples was recorded on a FT-IR instrument (Digital Excalibur 3000 series, Japan) with diffuse reflectance mode (DRS-800) attachment. All measurements were carried out in the range of $400-4,000 \mathrm{~cm}^{-1}$ at a resolution of $4 \mathrm{~cm}^{-1}$ (Saifuddin et al. 2009). 
X-ray diffraction analysis

The fungal mycelium embedded with the silver nanoparticles was freeze-dried, powdered and used for XRD analysis. The spectra were recorded in Philips ${ }^{\circledR}$ automatic X-ray Diffractometer with Philips ${ }^{\circledR}$ PW 1830 X-ray generator. The diffracted intensities were recorded from $30^{\circ}$ to $90^{\circ} 2 \theta$ angles.

\section{Antibacterial activity}

Biosynthesized silver nanoparticles produced by the $S$. radiatum were tested for antimicrobial activity as method suggested by Srinivasulu et al. (2002) using various Gram-positive and Gram-negative bacteria by the agar well-diffusion method. Approximately, $20 \mathrm{ml}$ of nutrient agar medium was poured into sterilized petri-dishes. The bacterial test organisms were grown in nutrient broth for $24 \mathrm{~h}$. A $100 \mu \mathrm{l}$ nutrient broth culture of each bacterial organism $\left(1 \times 10^{5} \mathrm{CFU} \mathrm{mm^{-1 }}\right)$ was used to prepare bacterial lawns. Agar wells of $8 \mathrm{~mm}$ diameter were prepared with the help of a sterilized stainless steel cork borer. The wells were loaded with $60 \mu \mathrm{l}$ of $\mathrm{Ag}$ nanoparticles solution, $60 \mu \mathrm{l}$ of $1.5 \mathrm{mM}$ silver nitrate and $60 \mu \mathrm{l}$ of culture broth from $S$. radiatum culture without $\mathrm{AgNO}_{3}$ as a negative control, along with $60 \mu \mathrm{l}$ of $30 \mu \mathrm{g}$ $\mathrm{ml}^{-1}$ of streptomycin as a positive control. The plates were incubated at $37{ }^{\circ} \mathrm{C}$ for $24 \mathrm{~h}$ and then were examined for the presence of zones of inhibition. The diameter of such zones of inhibition was measured and the mean value for each organism was recorded and expressed in millimeter unit.

\section{Results and discussions}

The 18S rRNA gene sequencing analysis of the isolate yielded 1,112 base pairs, and NCBI BLAST search analysis based on the topology of phylogenetic analysis revealed that the sequence was $99 \%$ related with $S$. radiatum. The obtained sequence was deposited in EMBL database with the Accession number HE 863742.1.

Biosynthesis of silver nanoparticles

Bioreduction of silver nitrate into nanosilver can be primarily characterized using UV-vis spectroscopy. In the present study, the color of the silver nitrate solution in the flask containing culture filtrate of $S$. radiatum changed from colorless to brown within $48 \mathrm{~h}$. Various concentrations of silver nitrate $(0.5,1.0,1.5,2.0$ and $2.5 \mathrm{mM})$ that were used, the formation of silver nanoparticles synthesis was observed at $1.5 \mathrm{mM}$ within $48 \mathrm{~h}$ (Fig. 1) and further increased with increase in silver nitrate concentration. An appreciable amount of silver nanoparticle was obtained at $2.5 \mathrm{mM}$ concentration. Kathiresan et al. (2009), working with silver nanoparticles in the range of 400-500 $\mathrm{nm}$ wave length, reported that there is a decrease in the value of optical density (OD) with a proportional increase in silver nitrate concentration. Extracts from organisms may act as reducing and capping agents in AgNPs synthesis. The reduction of silver ions by combinations of bio-molecules found in these extracts such as enzymes, proteins, amino acids, polysaccharides and vitamins is environmentally benign, yet chemically complex. But, the mechanism which is widely accepted for the synthesis of silver nanoparticles is the presence of enzyme "Nitrate reductase" (Anil Kumar et al. 2007; Kalimuthu et al. 2008). Cysteine a biomolecule present in the cell-free extract from Trichoderma asperellum acts as a potential reducing and capping agent in the synthesis of stable silver nanoparticles (Roy et al. 2011). From application point of view, the extracellular synthesis of nanoparticles is more important than the intracellular assimilations. Carbon sources such as glucose and fructose enhanced the production of enzyme which in turn reduced the silver nitrate hence the amounts of silver nanoparticles were improved. The time taken for the formation of silver nanoparticles appeared with in $48 \mathrm{~h}$ in glucose- and fructose-containing carbon sources. Lactose and galactose showed $72 \mathrm{~h}$, whereas starch has no influence on silver nanoparticle synthesis (Fig. 2).
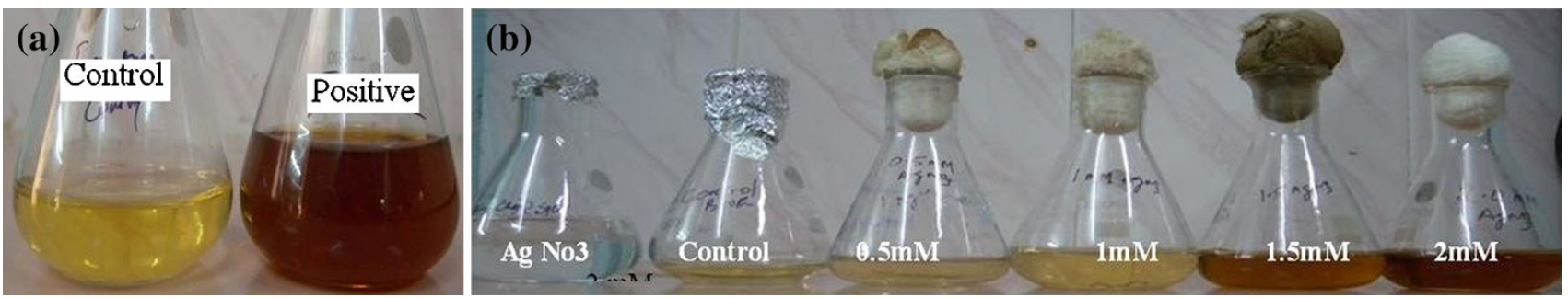

Fig. 1 a Showing the formation of silver nanoparticles after $48 \mathrm{~h}$ of incubation. b Effect of various concentrations of silver nitrate $\mathrm{AgNO}_{3}$ on nanoparticle synthesis 

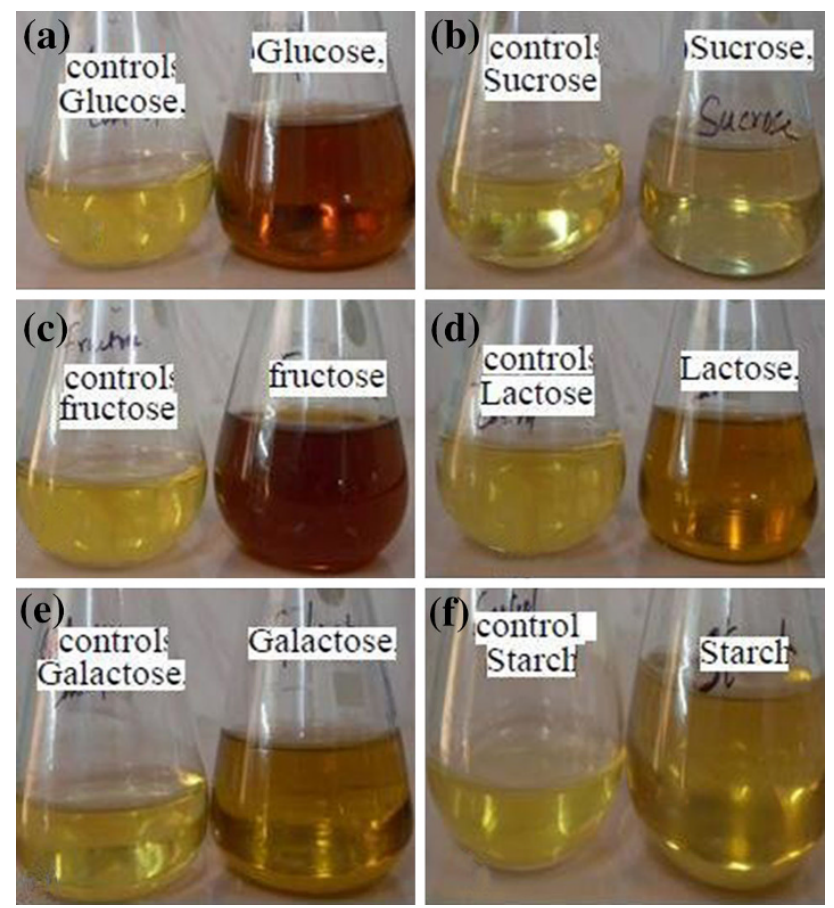

Fig. 2 Influence of carbon sources on nanoparticles synthesis a glucose, $\mathbf{b}$ sucrose, $\mathbf{c}$ fructose, $\mathbf{d}$ lactose, $\mathbf{e}$ galactose, $\mathbf{f}$ starch with respective controls

\section{Characterization of silver nanoparticles}

The homogeneous spherical silver nanoparticles are known to produce the surface plasmon resonance band at $413 \mathrm{~nm}$ (Ahmad et al. 2003). In the present system absorption maxima $\left(\lambda_{\max }\right)$ of biosynthesized silver nanoparticles (Fig. 3) observed in the range of $420-430 \mathrm{~nm}$. Brause et al. (2002), working with silver colloids in aqueous solution, reported that optical absorption spectra of metal nanoparticles are mainly dominated by surface plasmon resonance, and the absorption peak has relationship with particle size. Smaller AgNPs will have an absorbance maximum around $400 \mathrm{~nm}$, which increases with size and disappears when particle size falls outside nanodimensions.

\section{Scanning electron microscopy (SEM) analysis}

This SEM image (Fig. 4) provided further insight into the morphology and size of the produced nanoparticles. It is evident from the figure that the biosynthesized silver nanoparticles are in different size and shapes and mostly observed as individual particles as well as a few aggregates. SEM-mediated characterization of biosynthesized nanomaterials has been performed by several investigators. Particle size analysis revealed that the silver nanoparticles are in the size range of $10-40 \mathrm{~nm}$ with a mean diameter of $14.5 \mathrm{~nm}$ suggesting the production of different-sized nanoparticles. Silver nanoparticles in the range of 35-46 nm by Pseudomonas stutzeri (Klaus et al. 1999) 20-50 nm particles by Lactobacillus sp. (Nair and Pradeep 2002) 2-20 nm particles by Verticillium sp. and 2-50 nm sized particles by Fussarium oxysporum (Ahmad et al. 2003) have been reported. Mukherjee et al. (2008) demonstrated the synthesis of low dispersive and highly stabilized nanocrystalline silver particles by a non-pathogenic and agriculturally important fungus, Trichoderma asperellum.

Fourier-transform infrared (FT-IR) chemical analysis

FT-IR spectroscopy, used to characterize the surface chemistry of silver nanoparticles produced by $S$. radiatum
Fig. 3 UV-visible absorption spectra of silver nanoparticles after $48 \mathrm{~h}$ of incubation

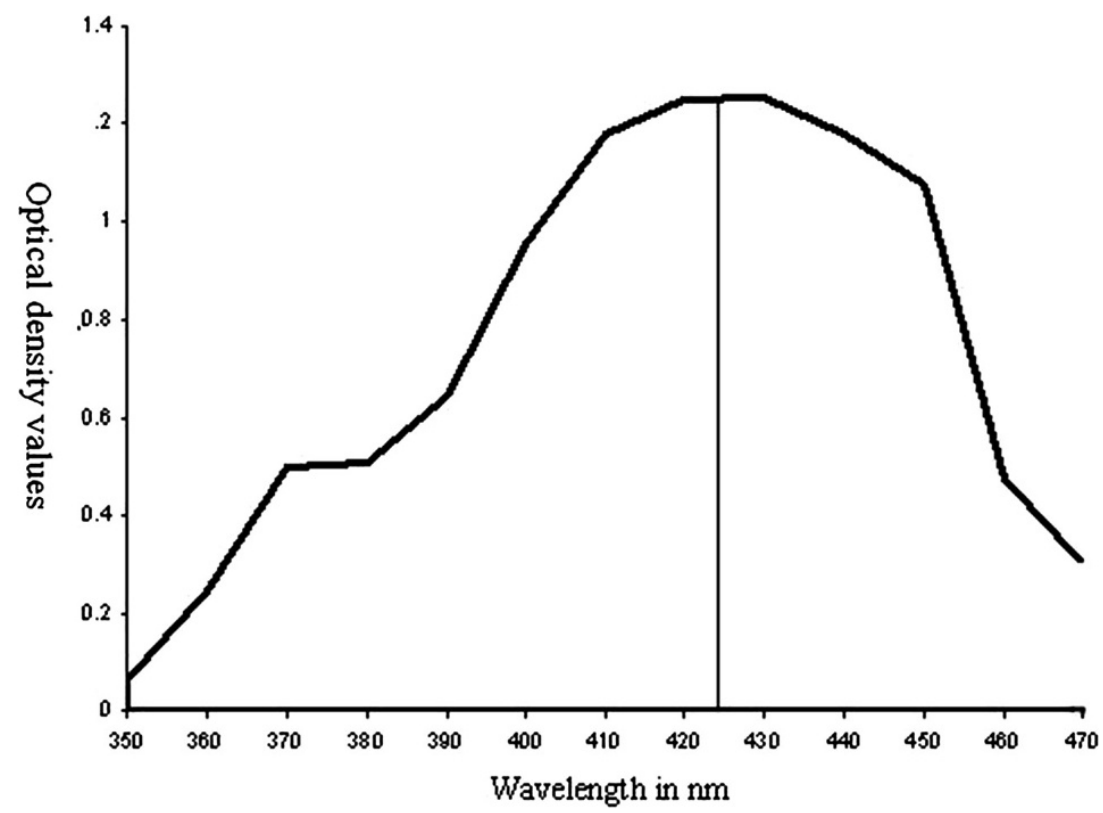


(Fig. 5), showed the FT-IR spectrum of the freeze-dried powder of silver nanoparticles formed after $48 \mathrm{~h}$ of reaction. The spectral data revealed two types of vibrations (i.e. stretching and bending) in the wavelength range of $4,000-500 \mathrm{~cm}^{-1}$. It is evident from the figure that the presence of an amine vibration band at $3,400 \mathrm{~cm}^{-1}$ represents a primary amine $(\mathrm{N}-\mathrm{H})$ stretching, and amide $(\mathrm{N}-$ $\mathrm{H})$ bending vibration bands at 1,650 and $1,644 \mathrm{~cm}^{-1}$. Furthermore, the FT-IR spectra of biosynthesized silver nanoparticles also revealed peaks at 2,026 and 2,116 cm stretching vibrations of aliphatic $\mathrm{C}-\mathrm{H}$ bonds. A band presence at $1,412 \mathrm{~cm}^{-1}$ can be assigned to $\mathrm{CH} 2$-scissoring stretching vibration at the planar region. Several $\mathrm{C}-\mathrm{N}$ stretching vibration peaks at 1,258, 1,143, 1,102, 1,027 and $908 \mathrm{~cm}^{-1}$ were also observed in the spectral range of 1,230-900 $\mathrm{cm}^{-1}$. In addition, the presence of bands at 1,356 and $1,250 \mathrm{~cm}^{-1}$ in the FT-IR spectra suggested that the capping agent of biosynthesized nanoparticles possesses an aromatic amine groups with specific signatures of amide linkages between amino acid residues in the proteins in the infrared region of the electromagnetic spectrum (Shaligram et al. 2009). This type of FT-IR spectra supports the presence of a protein type of compound on the surface of biosynthesized nanoparticles, confirming that metabolically produced proteins acted as capping agents during production and prevented the reduced silver particles agglomeration.

\section{X-ray diffraction analysis}

Freeze-dried reaction mixture embedded with the silver nanoparticles was used for X-ray diffraction (XRD) analysis. Crystallinity of biosynthesized silver nanoparticles was assessed from their X-ray powder diffraction patterns. The diffractogram showed (Fig. 6) the phase purity of the material. The diffraction peaks are above $37^{\circ}$, XRD patterns were recorded the four prominent 111, 200, 220 and 311 reflections at $2 \theta=38.2,44.4,64.5$ and 77.7 indicating the face centered cubic (FCC) structure of silver nanoparticles.
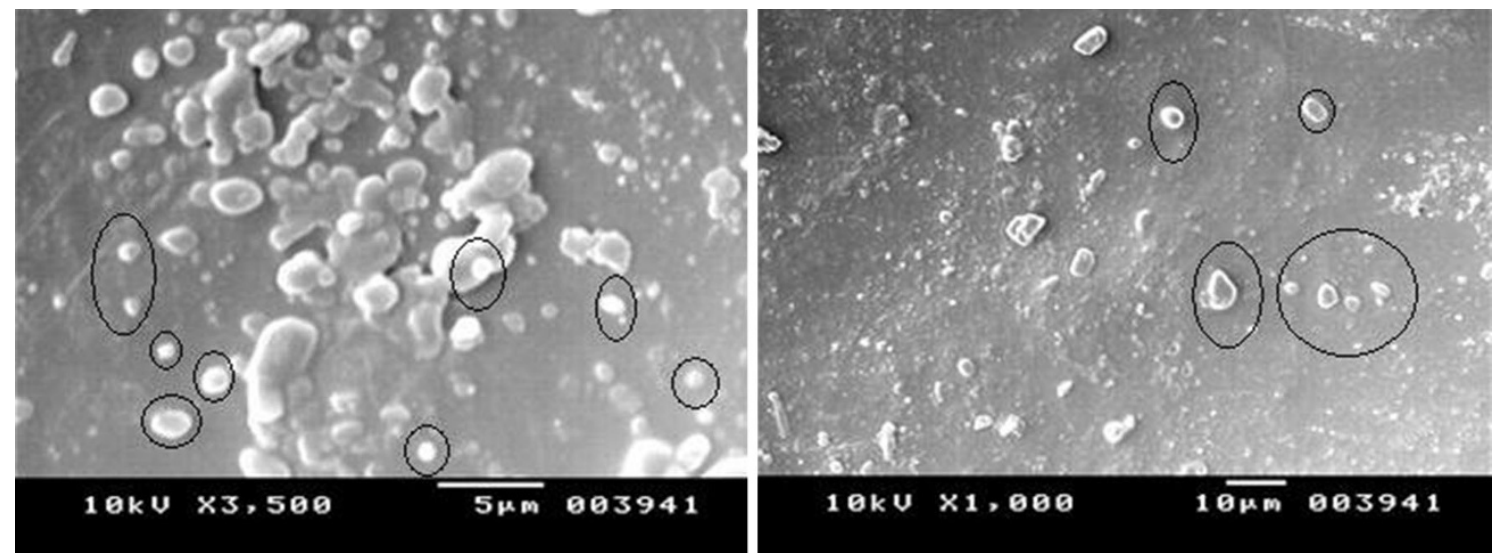

Fig. 4 Shows SEM micrographs of silver nanoparticles synthesized from fungal extracts

Fig. 5 FT-IR spectrum recorded with synthesized silver nanoparticles
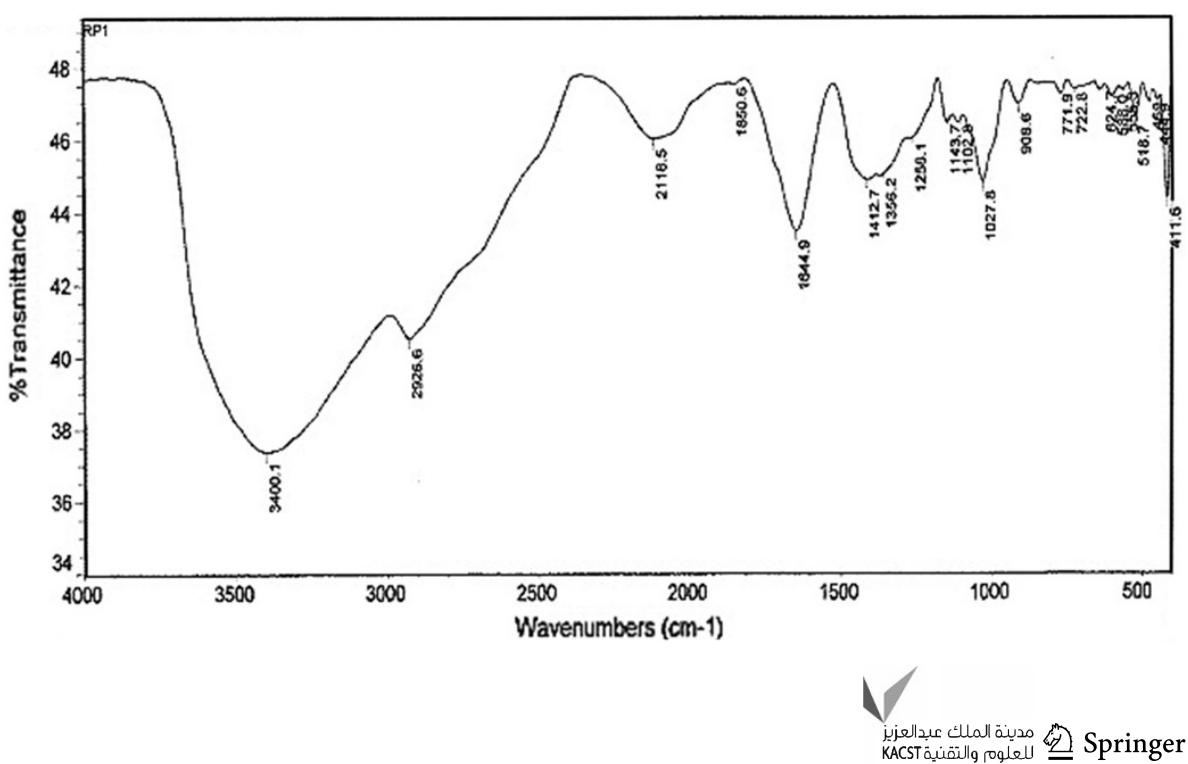


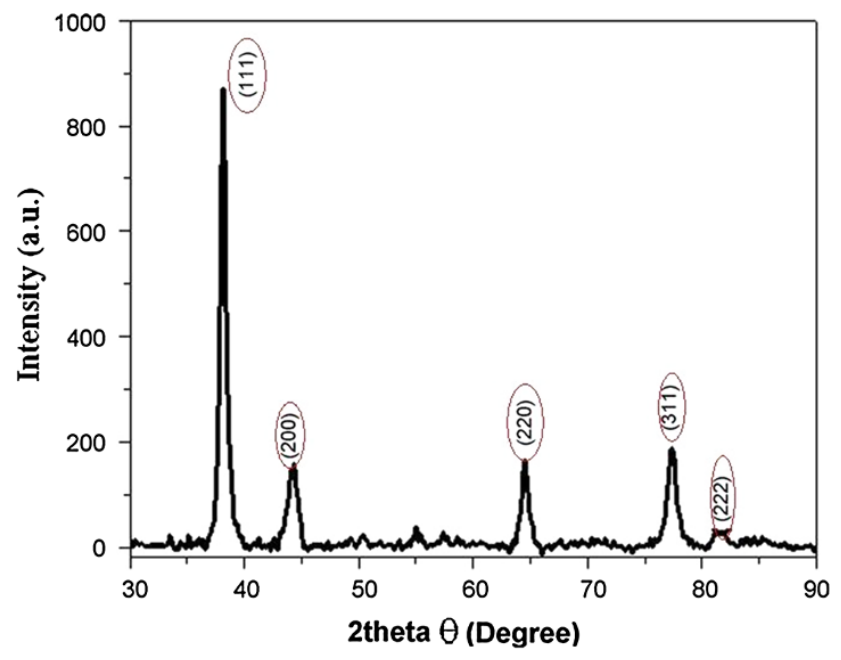

Fig. 6 XRD pattern of silver nanoparticles

Anti bacterial activity

Silver has been in use since time immemorial in the form of metallic silver, silver nitrate, silver sulfadiazine for the treatment of burns, wounds and several bacterial infections. But due to the emergence of several antibiotics the use of these silver compounds has been declined remarkably.
Silver in the form of silver nanoparticles has made a remarkable comeback as a potential antimicrobial agent and proved to be most effective as it has good antimicrobial efficacy against bacteria, viruses and other eukaryotic micro-organisms (Gong et al. 2007). The use of silver nanoparticles is also important, as several pathogenic bacteria have developed resistance against various antibiotics. The antibacterial activity of silver nanoparticles was investigated against various pathogenic Gram-positive and Gram-negative bacteria, like Escherichia coli, Klebsiella pneumoniae, Enterobacter aerogenes, Pseudomonas aeroginosa, Staphylococcus aureus, Salmonella paratyphi, Bacillus sterothermophilus, Bacillus subtilus using welldiffusion technique (Fig. 7). The diameter of inhibition zones around each well with $\mathrm{AgNPs}$ and $\mathrm{AgNO}_{3}$ is recorded in Table 1. The highest antimicrobial activity was observed against, B. subtilus and $S$. paratyphi, followed by Bacillus stearothermophilus, Staphylococcus aureus, Enterobacter aerogenes, Salmonella typhi and the least was noticed against Klebsiella pneumonia. Feng et al. (2000) reported the mechanism of silver nanoparticles action and used E. coli and $S$. aureus as model organisms. The nanoparticles get attached to the cell membrane and also penetrate inside the bacteria. The bacterial membrane contains sulfur-containing proteins and the silver
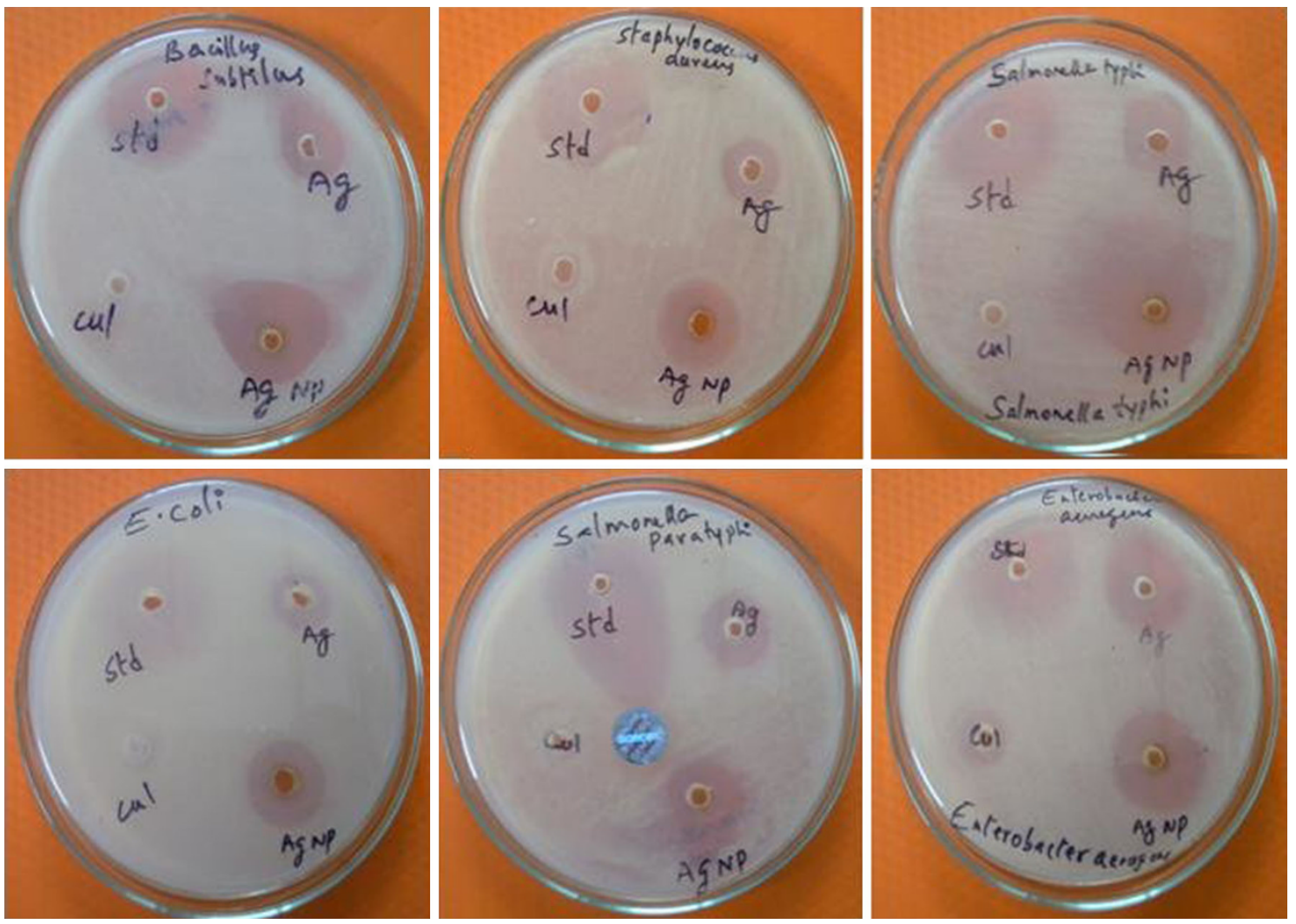

Fig. 7 Antibacterial activity of silver nanoparticles produced by Schizophyllum radiatum against bacterial species, where std standard (streptomycin), cul culture broth, $A g$ silver nitrate solution, $A g N P$ silver nanoparticles solution 
Table 1 Antibacterial activity of silver nanoparticles produced by Schizophyllum radiatum

\begin{tabular}{|c|c|c|c|}
\hline \multirow[t]{2}{*}{ Microorganism } & \multicolumn{3}{|c|}{ Zone of inhibition (mm) } \\
\hline & Streptomycin $^{\mathrm{a}}$ & $\begin{array}{l}\mathrm{AgNO}_{3} \\
\text { sol }^{\mathrm{b}}\end{array}$ & $\begin{array}{l}\text { Silver } \\
\text { nanoparticle sol }\end{array}$ \\
\hline Bacillus subtilus & 20 & 9 & 19 \\
\hline B. stearothermophilus & 24 & 13 & 17 \\
\hline Salmonella paratyphi & 24 & 8 & 19 \\
\hline S. typhi & 23 & 9 & 14 \\
\hline Staphylococcus aureus & 22 & 8 & 15 \\
\hline Pseudomonas aeroginosa & 23 & 9 & 13 \\
\hline Enterobacter aerogenes & 23 & 16 & 16 \\
\hline E. coli & 24 & 6 & 14 \\
\hline Klebsiella pneumoniae & 14 & 3 & 7 \\
\hline
\end{tabular}

nanoparticles interact with these proteins in the cell as well as with the phosphorus-containing compounds like DNA. Nanoparticles preferably attack the respiratory chain, cell division finally leading to cell death. Silver nanoparticles have emerged up with diverse medical applications in silver-based dressings (Duran et al. 2007).

\section{Conclusion}

The nanoscale understanding of the bioprocesses and interventions are only in infancy. The areas particularly bioprocess product exploitations are only in current focus that in itself has opened vistas in a technology upsurge. The order beneath the chaos at the genomic level is recognizable but not yet been fully understood. The microorganisms such as bacteria and algae have already proved to be inorganic nanofactories of the enormous dimensions. Among the different methods for NP synthesis, the chemical reduction method and green synthesis method were widely studied due to their advantage in controlling particle size and morphology. White rot fungus, easy to produce biomass and non-pathogenic nature will add strength to silver nanoparticles biosynthesis.

Acknowledgments The authors are thankful to Prof. S. Girisham, Head of the department Microbiology, Kakatiya University Warangal for providing laboratory facilities. We acknowledge the support extended by Sophisticated Analytical Instrumentation Facility at Department of Physics for analyzing the samples by SEM and FTIR.

Conflict of interest The authors declare that they have no conflict of interest.
Open Access This article is distributed under the terms of the Creative Commons Attribution License which permits any use, distribution, and reproduction in any medium, provided the original author(s) and the source are credited.

\section{References}

Agag T, Takeichi T (2000) Polybenzoxazine-montmorillonite hybrid nanocomposites synthesis and characterization. Polymer 41:7083-7090

Ahmad A, Mukherjee P, Senapati S, Mandal D, Khan MI, Kumar R, Sastry M (2003) Extracellular biosynthesis of silver nanoparticles using the fungus Fusarium oxysporum. Colloids Surf B 28:313-318

Anil Kumar S, Abyaneh MK, Gosavi Sulabha SW, Ahmad A, Khan MI (2007) Nitrate reductase mediated synthesis of silver nanoparticles from $\mathrm{AgNO}_{3}$. Biotechnol Lett 29:439-445

Bhattacharya D, Gupta RK (2005) Nanotechnology and potential microorganisms. Crit Rev Biotechnol 25:199-204

Brause R, Moeltgen H, Kleinermanns K (2002) Characterization of laser-ablated and chemically reduced silver colloids in aqueous solution by UV-vis spectroscopy and STM/SEM microscopy. Appl Phys B 75:711-716

Dahl JA, Maddux BLS, Hutchison JE (2007) Toward greener nanosynthesis. Chem Rev 107:2228-2269

Duran N, Marcarto PD, De Souza GIH, Alves OL, Esposito E (2007) Antibacterial effect of silver nanoparticles produced by fungal process on textile fabrics and their effluent treatment. J Biomed Nanotechnol 3:203-208

Elechiguerra JL, Burt JL, Morones JR, CamachoBragado A, Gao X, Lara HH, Yaca Man MJ (2005) Interaction of silver nanoparticles with HIV-I. J Nanobiotechnol 3:6-16

Feng QL, Wa J, Chen GQ, Cui KZ, Kim TM, Kim JO (2000) A mechanistic study of the antibacterial effect of silver ions on Escherichia coli and Staphylococcus aureus. J Biomed Mater Res 52:662-668

Gong P, Li H, He X, Wang K, Hu J, Tan W (2007) Preparation and antibacterial activity of $\mathrm{Fe}_{3} \mathrm{O}_{4} \mathrm{Ag}$ nanoparticles. Nanotechnology 18:604-611

Hampp N (2004) Bacteriorhodopsin and its potential in technical application. In: Niemeyer CM, Mirkin CA (eds) Nanobiotechnology concepts applications and perspectives. Wiley-VCH, New York, pp 146-167

Kalimuthu K, Babu RS, Venkataraman D, Mohd B, Gurunathan S (2008) Biosynthesis of silver nanocrystals by Bacillus licheniformis. Colloids Surf B 65:150-153

Kathiresan K, Manivannan S, Nabeel MA, Dhivya B (2009) Studies on silver nanoparticles synthesized by a marine fungus, Penicillium fellutanum isolated from coastal mangrove sediment. Colloids Surf B Biointerfaces 71:133-137

Klaus T, Joerger R, Olsson E, Granquist CG (1999) Silver based crystalline nanoparticles, microbially fabricated. Proc Natl Acad Sci USA 96:13611-13614

Kuber CB, Souza SF (2006) Extracellular biosynthesis of silver nanoparticles using the fungus Aspergillus fumigatus. Colloids Surf B 47:160-164

Lengke MF, Fleet ME, South G (2007) Biosynthesis of silver nanoparticles by filamentous cyanobacteria from a silver (I) nitrate complex. Langmuir 23:2694-2699

Mandal D, Bolander ME, Mukhopadhyay D, Sarkar G, Mukherjee P (2006) The use of microorganisms for the formation of metal nanoparticles and their application. Appl Microbial Biotechnol 69:485-492 
Morones JR, Elechiguerra JL, Camacho A, Holt K, Kouri JB, Tapia J, Jose Yacaman M (2005) The bactericidal effect of silver nanoparticles. Nanotechnology 16:2346-2353

Mukherjee P, Roy M, Mandal B, Dey G, Mukherjee P, Ghatak J (2008) Green synthesis of highly Stabilized nanocrystalline silver particles by a non-pathogenic and agriculturally important fungus T. asperellum. Nanotechnology 19:75103-75110

Nair B, Pradeep T (2002) Coalescence of nanoclusters and formation of sub-micron crystallites assisted by Lactobacillus strains. Crystal growth Design 4:295-298

Roy M, Mukherjee P, Mandal P, Sharma K, Tyagi K, Kale P (2011) Biomimetic synthesis of nano crystalline silver sol using cysteine: stability aspects and antibacterial activities. RSC Advances 2:6496-6503
Saifuddin N, Wang WC, Nur Yasumira AA (2009) Rapid biosynthesis of silver nanoparticles using culture supernatant of bacteria with microwave irradiation. E J Chem 6:61-70

Shaligram SN, Bule M, Bhambure R, Singhal SR, Singh K, Szakacs S, Pandey A (2009) Biosynthesis of silver nanoparticles using aqueous extract from the compacting producing fungi. Process Biochem 44:939-943

Shiying H, Zhirui G, Yu Z, Song Z, Jing W, Ning G (2007) Biosynthesis of gold nanoparticles using the bacteria Rhodo pseudomonas capsulate. Mater Lett 61:3984-3987

Srinivasulu B, Prakasham RS, Jetty A, Srinivas S, Ellaiah P, Ramakrishna SV (2002) Neomycin production with free and immobilized cells of Streptomyces marinensis in an airlift reactor. Process Biochem 38:593-598 